Infection

\title{
Advances in the prevention and treatment of paediatric HIV infection in the United Kingdom
}

\section{Sharland, D M Gibb, G Tudor-Williams}

\section{A summary of recent developments}

t

$\mathrm{n}$ the five years since our last review there have been considerable advances, both in the prevention of mother to child transmission (MTCT) of HIV, and in the treatment of HIV infected children with highly active antiretroviral therapy (HAART). ${ }^{1}$ There are now over 600 children living with HIV in the UK, the majority of whom were born to mothers who acquired HIV in Africa. Currently, about two thirds live in London, but this may change if refugees continue to be dispersed to other parts of the country. Antenatal testing for HIV has been shown to be cost effective throughout the UK. ${ }^{3}$ However, although uptake of testing has increased in London, rates of detection of previously undiagnosed women during pregnancy are about $60 \%$ outside London. ${ }^{2}$ HIV infected babies are still presenting seriously ill and dying with Pneumocystis carinii pneumonia (PCP) in the first months of life. ${ }^{4}$ In 1999 the Department of Health (DoH) set targets that by the end of 2002, all UK health authorities should increase uptake of antenatal HIV testing to $90 \%$, with the aim that $80 \%$ of HIV infected pregnant women nationally would be identified and offered treatment. ${ }^{5}$ These targets will only be met if testing rates are increased outside London. ${ }^{6}$ Paediatricians throughout the UK need to be familiar with how MTCT of HIV is prevented, and how to manage children born to HIV infected mothers. This paper summarises the recent developments in prevention and management of HIV infected children.

\section{MOTHER TO CHILD TRANSMISSION OF HIV INFECTION}

The rate of MTCT prior to the advent of interventions in Europe and USA was around 15-20\%, compared with about $30 \%$ in Africa. Most of this difference is a result of breast feeding, which approximately doubles the transmission rate. In non-breast feeding populations, around two thirds of MTCT occurs around the time of delivery. The increased uptake of interventions in pregnancy between 1995 and 2001 has led to vertical transmission rates falling below $2 \%$ in women diagnosed antenatally. ${ }^{7}$ These interventions include the use of perinatal antiretroviral therapy (ART), ${ }^{8}$ elective caesarean delivery, ${ }^{9}$ and not breast feeding. ${ }^{10}$ ART reduces MTCT by decreasing maternal viral load and by providing pre- and post-exposure prophylaxis to the infant. An increasing proportion of women are taking triple ART during pregnancy. MTCT rates below $1 \%$ are being reported among women on HAART with undetectable HIV viral load at delivery. ${ }^{7}$ Guidelines on the management of HIV infected women during pregnancy and the follow up of their infants are available and regularly updated. ${ }^{11}{ }^{12}$ In the UK, over $95 \%$ of women who know their HIV status in pregnancy take up these interventions. ${ }^{13}$ Concerns about toxicity of ART in pregnancy were raised by reports of mitochondrial dysfunction in HIV uninfected infants exposed to ART in pregnancy, ${ }^{14}$ but this is likely to be rare as it has not been observed after extensive retrospective reviews of other large cohorts. ${ }^{1}$ Although additional concerns about the potential carcinogenicity and reproductive effects of perinatal ART also remain, current evidence strongly suggests that the benefit of ART to reduce MTCT far outweighs potential harm. In the UK, long term surveillance of uninfected children born to HIV infected mothers will be coordinated through the National Study of HIV in Pregnancy at the Institute of Child Health (ICH).

The case for routinely offering and recommending HIV testing as an integral part of routine antenatal care for women is now overwhelming, and in the UK has been accepted by professionals and government for all parts of the country, not just London. In 1998, an Intercollegiate Working Party recommended that HIV testing be "normalised" during pregnancy and urgently integrated into routine antenatal testing. ${ }^{16}$ Studies have shown that the uptake of testing by women is most affected by the attitude of the health provider offering testing, and is not necessarily related to the time taken to offer the test, the place of antenatal booking, or the extent of discussion. ${ }^{17}$ Simple information that HIV MTCT can be prevented has now been incorporated into written leaflets on antenatal screening tests in most London maternity units. The DoH leaflet can be downloaded from the web (www.doh.gov.uk/ eaga/betterbaby.htm) and can be integrated into information given on all routine screening tests at the time of booking. The HIV test is then taken as part of the normal booking bloods, with no other counselling unless the woman requests further information. Women found to be infected need considerable support from a multidisciplinary team. In the past two years, there has been an increase in the proportion of previously undiagnosed women detected during pregnancy, rising from less than $20 \%$ to over $80 \%$ in inner London and from very low levels to around $60 \%$ outside London. ${ }^{2}$ High levels of uptake of antenatal HIV testing can be achieved outside London in low prevalence areas. ${ }^{18}$ Achieving the DoH targets by the end of 2002 is principally the responsibility of those providing antenatal care. However, paediatricians also have an important role in ensuring that this work is underway locally. Otherwise, even in low prevalence areas, they will be faced with children whose HIV infection could have been prevented.

\section{MANAGING HIV INFECTED CHILDREN}

HIV infection should be considered in the differential diagnosis of a wide variety of paediatric conditions. Too often in the UK opportunities for making an earlier diagnosis have been missed. ${ }^{19}$ There are two principle categories of infected children. One fifth of children infected perinatally develop rapidly progressive symptomatic disease, typically presenting with $P$ carinii pneumonia around 10-14 weeks of age, or developmental delay or regression in the first year of life. This mode of presentation will decline with the successful implementation of antenatal screening. The other four fifths of perinatally infected children have a median survival without treatment of around nine years, and a proportion do not present until the second decade of life. Such children may have been born in the UK before screening was undertaken, or have been born abroad, or received blood products in high HIV seroprevalence areas such as subSaharan Africa, South East Asia, and increasingly India, Eastern Europe, the Caribbean, Latin America, and China. We should be testing more children who

Reproduced in full with permission from Arch Dis Child 2002;87:178-180. 
present with lymphadenopathy, hepatosplenomegaly, persistent parotid enlargement, shingles, extensive molluscum, thrombocytopenia, recurrent infections, failure to thrive, or unexplained organ disease.

All paediatricians in collaboration with local genitourinary medicine (GUM) centres should be able to hold a sensitive pretest discussion with caregivers, explaining the benefit of early diagnosis, and the implications of a positive result for the family. ${ }^{20}$ If a child is being adopted or entering long term foster care, consideration should be given to testing for HIV, and hepatitis B and C. Ideally maternal consent should be sought, to enable the mother to seek appropriate help for herself if any blood borne viruses are detected.

\section{"Seventeen antiretrovirals are now available for children"}

Combination ART has converted HIV into another treatable chronic disease of childhood. From around 1988-94 only one drug was available-zidovudine (ZDV, AZT). Dual therapy was introduced in 1994-97, and triple therapy followed in 1998-99. Seventeen antiretrovirals are now available for children. Sustained control of viral replication requires three or more drugs in combination. Even before the introduction of triple ART, mortality rates from HIV were decreasing, probably because of increased use of prophylaxis to reduce opportunistic infections such as PCP and the use of dual ART. $^{21}{ }^{22}$ The introduction of HAART has led to further reductions in disease progression and mortality in Europe and North America. Eradication of HIV is not possible with the current drugs, and children will probably have to stay on some form of therapy life long. Most children on HAART remain clinically very well, thriving normally, and asymptomatic. The CD4 cell count (predominantly CD45RA+, naïve $\mathrm{T}$ cells) may continue to increase for many months, although immunological abnormalities persist in vitro.

Obstacles to long term successful treatment include poor adherence related to unpleasant tasting suspensions or many large tablets, short and long term adverse effects (including abnormal lipid, glucose, and bone metabolism), and lack of family routines. There are still limited pharmacokinetic data for

Abbreviations: ART, antiretroviral therapy; DoH, Department of Health; HAART, highly active antiretroviral therapy; $\mathrm{ICH}$, Institute of Child Health; MTCT, mother to child transmission; PCP, Pneumocystis carinii pneumonia many antiretrovirals, particularly in infants and adolescents, and therapeutic drug monitoring is increasingly used. Older children need to gradually learn the details of their diagnosis to enable them to take increasing responsibility for their own health, and certainly before they become sexually active. With effective multidisciplinary support from health professionals and voluntary sector organisations, the majority of infected children will survive into adulthood, and transitional care to GUM services must be anticipated.

It is not clear when HAART should be started. Children with AIDS defining conditions or severe immunosuppression (CD4 <15\%, particularly if falling) should start HAART immediately. Minimally symptomatic children with stable CD4 percentages $>20 \%$ can have treatment deferred. In most children good immune reconstitution is achieved, but there is frequently incomplete suppression of viral replication. This leads in time to selection of drug resistant virus, virological failure, declining CD4 counts, and the need to sequence onto new drug combinations. Children should be treated in accordance with the PENTA (Pediatric European Network for the Treatment of AIDS) Guidelines on ART use in HIV infected children. ${ }^{23}$ Many questions remain to be answered and entry into clinical trials should be encouraged. Novel strategies for boosting HIV specific immune responses are under investigation. In Europe, trials of antiretroviral therapy and other treatment modalities are conducted through the PENTA network (www.pentatrials. org).

The clinical management of children with HIV is increasingly complex, and ideally should be provided in a family clinic setting that meets the needs of all family members, including uninfected but affected siblings. Clinical governance would strongly suggest that now all infected children should only be managed in service networks in collaboration with one of the specialist paediatric HIV multidisciplinary teams (see below) ${ }^{24}$ This is in line with the new national $\mathrm{DoH}$ Sexual Health and HIV Strategy. ${ }^{20}$ The Collaborative HIV Paediatric Surveillance (CHIPS, coordinated from the MRC Clinical Trials Unit in collaboration with ICH) is now collating details of all HAART use and clinical and surrogate marker outcome data for HIV infected children attending 14 hospitals. Paediatricians, nurses, and other health professionals interested in HIV in children have formed the Children's HIV Association (CHIVA) as a subgroup of the British HIV Association.

Worldwide UNAIDS estimate that 2.7 million children are living with HIV, of whom only $1 \%$ live in Europe and the USA. A further 4.5 million infected children have died, and over 13 million have been orphaned. In many sub-Saharan countries, between a third to a half of all under 5 mortality is now a result of AIDS..$^{25}$ Perinatally infected children in Africa may have mortality rates of over $80 \%$ in the first three years of life. ${ }^{26} \mathrm{HIV}$ is slowing economic development in many countries, and there is an urgent need to support HIV prevention and treatment programmes through international agencies and through hospital to hospital (UK-resource poor country) initiatives. $^{27}$

The highly mutable virus is an elusive target for vaccine development. The International AIDS Vaccine Initiative is putting into place structures for large studies, as vaccines remain the principle hope for global control.

\section{CONTACT DETAILS}

Family HIV Clinic, Paediatric Infectious Diseases Unit, St George's Hospital, Blackshaw Road, London SW17 0QT; Tel/ Fax 02087253262.

Family HIV Clinic, Hospital for Sick Children, Great Ormond Street, London WCIN 3JH; Tel 02078138231.

Family HIV Clinic, Dept of Paediatrics, St Mary's Hospital, 6th Floor QEQM Wing, Praed St, London W2 1NY; Tel 0207886 6349.

Medical Research Council, Clinical Trials Unit, 222 Euston Road, London NWl 2DA; Tel 0207670 4791; www.ctu.mrc.ac.uk\penta; Penta@ctu.mrc.ac.uk.

Body and Soul, 60 Great Ormond Street, London WC1N 3HR; Tel 0207833 4828; www.bodyandsoul.demon.co.uk.

Paediatric Infectious Diseases Unit, Our Lady's Hospital for Sick Children, Dublin 12, Ireland.

Sex Transm Infect 2003;79:53-55

\section{Authors' affiliations}

M Sharland, Paediatric Infectious Diseases Unit, St George's Hospital, Blackshaw Road, London SWI7 OQT, UK

D M Gibb, Clinical Trials Unit, Medical Research Council, 222 Euston Road, London NW1 2DA, UK

G Tudor-Williams, Paediatric Infectious Diseases Unit, St Mary's Hospital, 6th Floor QEQM Wing, Praed St, London W2 INY, UK

Correspondence to: Dr M Sharland, Paediatric Infectious Diseases Unit, St George's Hospital, Blackshaw Road, London SW17 OQT, UK; msharlan@sghms.ac.uk

\section{REFERENCES}

1 Sharland M, Gibb D, Tudor-Williams G, et al. Paediatric HIV infection. Arch Dis Child 1997;76:293-6.

2 Improvement in antenatal screening for HIV in the United Kingdom. CDR Weekly November 2001 (www.phls.org.uk/publications).

3 Ades AE, Sculpher MS, Gibb DM, et al. Cost effectiveness analysis of antenatal HIV screening in the United Kingdom. BM 1999;319:1230-4. 
4 Williams AJ, Duong T, McNally LM, et al. Pneumocystis carinii pneumonia and cytomegalovirus infection in children with vertically acquired HIV infection. AIDS 2001;15:335-9.

5 Reducing mother to baby transmission of HIV. Health Service Circular 183, 1999.

6 Cliffe S, Tookey PA, Nicoll A. Antenatal detection of HIV: national surveillance and unlinked anonymous survey. $B M$ 2001;323:376-7.

7 Goedert JJ, Gray L, Korber BT, et al. Perinatal transmission of HIV-1 from pregnant women with RNA viral load less than 1000 copies/ml [abstract 517]. 8th Conference on Retroviruses and Opportunistic Infections, Chicago, 2001.8

8 Connor EM, Sperling RS, Gelber R, et al. Reduction of maternal-infant transmission of human immunodeficiency virus type 1 with zidovudine treatment. N Engl J Med 1994;331:1173-80.

9 European Mode of Delivery Collaboration. Elective caesarean section versus vaginal delivery in prevention of vertical HIV-1 transmission: a randomised clinical trial. Lancet 1999;353:1053-9

10 Dunn D, Newell ML, Ades A, et al. Risk of human immunodeficiency virus type 1 transmission through breast feeding. Lancet 1992;340:585-8.

11 Taylor G, Lyall E, Mercey D, et al. British HIV Association Guidelines for prescribing antiretroviral therapy in pregnancy. Sex Transm Inf 1999;75:90-7 (200) www.bhiva.org).
12 Public Health Service Task Force. Recommendations for the use of antiretrovira drugs in pregnant women infected with HIVfor maternal health and reducing perinatal HIV-1 transmission in the United States (live document www. hivatis.org ).

13 Duong T, Ades AE, Gibb DM, et al. Vertical transmission of HIV in the British Isles: estimates based on surveillance data. BM 1999:319:1227-9.

14 Blanche S, Tardieu M, Rustin $P$, et al. Persistent mitochondrial dysfunction and perinatal exposure to antiretroviral nucleoside analogues. Lancet 1999;354:1084-9.

15 Dominguez K, Bertolli J, Fowler $M$, et al. Lack of definitive severe mitochondrial signs or symptoms among deceased HIV uninfected and HIV indeterminate children $<5$ years of age, Pediatric Spectrum of Disease Project (PSD), USA. Ann N Y Acad Sci 2000:918:236-46.

16 RCPCH. Reducing mother to child transmission of HIV infection in the United Kingdom. Recommendations of an Intercollegiate Working Party for Enhancing Voluntary Confidential HIV Testing in Pregnancy. RCPCH, April 1998 (www.rcpch.ac.uk).

17 Gibb DM, MacDonagh SE, Gupta R, et al Factors affecting uptake of antenatal HIV testing in London: results of a multicentre study. BM 1998;316:259-61.

18 Dean G, Fisher M, Ottewill M. Uptake of antenatal screening for HIV infection can be high outside London too. BM 2001;323:1188.
19 Richardson MP, Sharland M. Late diagnosis of paediatric HIV infection in south west London. BM 1998;318:271-2.

20 Kinghorn G. A sexual health and HIV strategy for England. BM 2001;323:243-4.

21 PENTA. Five year follow up of vertically HIV infected children in a randomised double blind controlled trail of immediate versus deferred zidovudine: the PENTA 1 trial. Arch Dis Child 2001;84:230-6.

22 Duong T, McGee L, Sharland $M$, et al. Effects of antiretroviral therapy (ART) on morbidity and mortality of the UK and Irish HIV infected children. Arch Dis Child 2002;86 (suppl 1):A69.

23 Sharland M, Castelli G, Ramos J, et al for the PENTA Steering Committee. PENTA

Guidelines for antiretroviral therapy use in HIV infected children. HIV Medicine 2002;3:1-12

24 Doerholt K, Sharland M, Ball C, et al. Paediatric antiretroviral therapy audit in south London. HIV Medicine 2002;2: 1-5.

25 UNAIDS. Report on the global HIV/AIDS epidemic. Joint United Nations Programme on HIV/AIDS, 2000 (www.unaids.org).

26 Taha TE, Graham SM, Kumwende NI, et al. Morbidity among HIV-1 infected children and uninfected African children. Pediatrics 2000;106:e77.

27 Centers for Disease Control and Prevention, Global Aids Program (www.cdc.gov/nchstp/od/gap) and Department for International Development (www.dfid.gov.uk). 